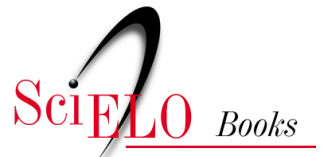

\title{
2. Método, locais e caminhos da pesquisa
}

\author{
Armelle Giglio-Jacquemot
}

\section{SciELO Books / SciELO Livros / SciELO Libros}

GIGLIO-JACQUEMOT, A. Método, locais e caminhos da pesquisa. In: Urgências e emergências em saúde: perspectivas de profissionais e usuários [online]. Rio de Janeiro: Editora FIOCRUZ, 2005, pp. 31-43. Antropologia e Saúde collection. ISBN: 978-85-7541-378-4. https://doi.org/10.7476/9788575413784.0004.

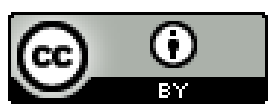

All the contents of this work, except where otherwise noted, is licensed under a Creative Commons Attribution 4.0 International license.

Todo o conteúdo deste trabalho, exceto quando houver ressalva, é publicado sob a licença Creative Commons Atribição 4.0.

Todo el contenido de esta obra, excepto donde se indique lo contrario, está bajo licencia de la licencia Creative Commons Reconocimento 4.0. 


\section{2 \\ Método, Locais e Caminhos da Pesquisa}

\section{MrRílLIA}

No oeste do Estado de São Paulo, na região denominada Alta Paulista, localizase a cidade de Marília, onde foi realizada a pesquisa que deu origem a este livro. Nascido da incorporação de três povoados ${ }^{1}$ que se desenvolveram com o café, ao longo de uma primeira picada aberta em 1913, o município de Marília ocupa hoje uma área territorial de $1.170 \mathrm{~km}^{2}$ e conta com uma população de 197.342 moradores, em grande parte urbana e alfabetizada, e em crescimento. ${ }^{2}$

A economia do município está centrada nos ramos da agricultura, pecuária, silvicultura, sericicultura e indústria de transformação. A produção agropecuária é bastante diversificada, com predominância do cafẻ, milho, pecuária de leite e corte. No que diz respeito às indústrias, prevalecem as de pequeno porte, com destaque para as indústrias de metalurgia. $O$ município também concentra um grande número de indústrias alimentícias, particularmente voltadas à produção de balas, doces e biscoitos. Elas dão a Marília seu cheiro característico de bolo assando e conferem-lhe o título de Capital Nacional do Alimento. Mas é o setor terciário o maior responsável pela ocupação da população economicamente ativa.

Marília também é um pólo universitário importante do interior paulista. Ela possui duas universidades: uma pública, que é uma unidade da Universidade Estadual Paulista (Unesp), voltada para as áreas de filosofia e ciências; e uma privada, a Universidade de Marília (Unimar). Tem ainda duas fundações: uma privada, a Fundação de Ensino Eurípides Soares da Rocha, que ministra cursos de administração, ciências contábeis e direito; uma pública, a Fundação Municipal de Ensino Superior, responsável pela Faculdade de Medicina de Marília (Famema), que funciona em conjunto com o Hospital das Clínicas - hospital universitário - onde o campo etnográfico elegeu um de seus locais de investigação privilegiados, isto é, o pronto-socorro.

Com relação ao nível de renda da população na área de abrangência do município, em 2000, 42,06\% das pessoas responsáveis pelos domicílios tinham uma renda situada entre menos de meio a três salários mínimos. Concluindo-se que uma parte significativa da população é dependente e usuária dos serviços de acesso gratuito do Sistema Único de Saúde (SUS). 


\section{A Área da Saúde}

\section{Os Serviços de Saúde}

Marília faz parte da área de abrangência da DIR-XIV. É servida por uma rede de serviços de saúde, alguns sob a gerência do município ou do estado, outros sob a gerência de entidades filantrópicas e de serviços privados. Na época da coleta dos dados, em 1998, ${ }^{3}$ eles eram os seguintes e assim distribuídos:

Quadro 1 - Distribuição dos serviços de saúde em função da gerência

\begin{tabular}{|c|c|c|c|}
\hline $\begin{array}{l}\text { SOB A GERÂCIA } \\
\text { DO MUNICIPIO }\end{array}$ & $\begin{array}{l}\text { Sob a GeRÂnCIA } \\
\text { DO ESTADO }\end{array}$ & $\begin{array}{c}\text { SOB A GERINCIA } \\
\text { DE ENTDADES } \\
\text { FILANTRÓPICAS }\end{array}$ & $\begin{array}{l}\text { Sob a GerRácia de } \\
\text { Serviços Privados }\end{array}$ \\
\hline $\begin{array}{l}26 \text { Unidades Básicas de } \\
\text { Saúde (UBS) }\end{array}$ & $\begin{array}{l}2 \text { hospitais universitários: } \\
\text { Hospital das Clinicas } \\
\text { e Hospital Municipal } \\
\text { (referência rcgional de } \\
\text { atendimento terciário) }\end{array}$ & $\begin{array}{c}\text { Santa Casa de } \\
\text { Misericórdia }\end{array}$ & $\begin{array}{l}23 \text { serviços } \\
\text { ambulatoriais }\end{array}$ \\
\hline 1 centro de saúde & $\begin{array}{c}1 \text { faculdade de medicina: } \\
\text { Famema }\end{array}$ & $\begin{array}{l}\text { Hospital Espírita } \\
\text { (psiquaítrico) }\end{array}$ & $\begin{array}{l}328 \text { consultórios e } \\
\text { clínicas médicas }\end{array}$ \\
\hline $\begin{array}{l}59 \text { consultórios } \\
\text { odontológicos }\end{array}$ & $\begin{array}{l}1 \text { curso enfermagem } \\
1 \text { curso de fonoaudiologia } \\
\text { (Unesp) }\end{array}$ & $\begin{array}{c}\text { Hospital São Francisco } \\
\text { de Assis }\end{array}$ & $\begin{array}{c}1 \text { faculdade de medicina } \\
\text { (Unimar) }\end{array}$ \\
\hline- & $\begin{array}{l}\text { Núcleo de Gestão } \\
\text { Assistencial }\end{array}$ & $\begin{array}{l}\text { Hospital Maternidade } \\
\text { Gota de Leite }\end{array}$ & - \\
\hline - & Laboratório Adolfo Luz & - & - \\
\hline - & Hemocentro & - & - \\
\hline
\end{tabular}

Fonte: Plano de Saúde do município de Marília (1997). 


\section{Os Prontos-Socorros}

Com relação ao atendimento de urgência e de emergência nos hospitais, a cidade possui quatro prontos-socorros cuja capacidade operacional e de resolubilidade varia segundo os lugares. Eles são assim classificados:

Quadro 2 - Caracterização do atendimento segundo os prontos-socorros

\begin{tabular}{|c|c|}
\hline Hospital & Características do Pronto-Socorro \\
\hline Hospital das Clínicas & $\begin{array}{l}\text { Atendimento de urgêneias/emergências clínicas e cirúrgicas com } \\
\text { traumato-ortopedia e Unidade de Terapia Intensiva. }\end{array}$ \\
\hline Santa Casa de Miscricórdia & $\begin{array}{l}\text { Atendimento de urgências/cmergências clínicas e cirírgicas } \\
\text { com traumato-ortopedia e Unidade de Terapia Intensiva. }\end{array}$ \\
\hline São Francisco de Assis & $\begin{array}{l}\text { Atendimento de urgências/cmergêneias clínicas c cirúrgicas } \\
\text { com traumato-ortopedia }\end{array}$ \\
\hline $\begin{array}{l}\text { Maternidade } \\
\text { Gota de Leite }\end{array}$ & Atendimento de urgências/ennergêneias clínicas e cirúrgicas \\
\hline
\end{tabular}

Fonte: Projeto de urgência e emergência da DIR-XIV - Marília - 1998.

O pronto-socorro do Hospital das Clínicas (com funcionamento $24 \mathrm{~h}$ por dia) é responsável pelo maior número de atendimentos. Em novembro de 1997, bem no início do trabalho de campo, o pronto-socorro do Hospital Municipal - onde eram prestados os atendimentos nas áreas de clínica médica, cirurgia geral e especializada, psiquiatria, ortopedia e oftalmologia - foi transferido para o pronto-socorro do Hospital das Clínicas, que, atuando até então somente nas áreas de pediatria (clínica e cirúrgica), ginecologia e obstetrícia, passou a atender em todas as áreas. A tabela seguinte testemunha o número importante de atendimentos por ele realizado:

Tabela 1 - Quantidade de atendimentos prestados pelo pronto-socorro do Hospital das Clínicas nos seis primeiros meses de 1998

\begin{tabular}{l|c|c|c|c|c|c|c}
\hline \multicolumn{1}{|c|}{ PS do HC } & Jan. & Fev. & Mar. & Abr. & Maio. & Jun. & Torsl, \\
\hline Quantidade atendida & 10.533 & 11.578 & 14.315 & 15.316 & 15.983 & 16.475 & 84.200 \\
\hline Quantidade atendida por sexo: & & & & & & & \\
- Homens & 5.364 & 5.945 & 7.276 & 7.813 & 8.116 & 8.106 & 42.620 \\
- Mulheres & 5.169 & 5.633 & 7.039 & 7.503 & 7.867 & 8.369 & 41.580 \\
\hline Quantidade atendida por DIR: & & & & & & & \\
- Marilia & 9.148 & 10.146 & 12.557 & 13.341 & 14.074 & 14.645 & 73.911 \\
- Outros DIR & 1.062 & 1.127 & 1.416 & 1.622 & 1.636 & 1.551 & 8.414 \\
- Não informados c não classificados & 323 & 305 & 342 & 353 & 273 & 279 & 1.875 \\
\hline
\end{tabular}

Fonte: Setor de Estatística Médica do Hospital das Clínicas de Marília. 


\section{As Centrais de Cilimiadas}

Pertencem também à rede pública de atendimento às urgências e emergências da cidade duas centrais de chamadas com sistema de atendimento móvel e funcionamento $24 \mathrm{~h}$ por dia: o 193 e o 192 . Os veículos e profissionais dessa ajuda móvel atendem as pessoas nos locais onde se encontram (casa, rua etc.), dão-lhes uma assistência médica de primeiro-socorro, e as conduzem para os prontos-socorros da cidade, geralmente o do Hospital das Clínicas.

O 193 é a Central do Corpo de Bombeiros que recebe solicitações de intervenções por meio deste número de telefone gratuito tanto para situações específicas de bombeiro, como incêndio, por exemplo, quanto para atendimentos de urgência de todas as modalidades. A recepção das chamadas e sua triagem são realizadas por bombeiros do Comando de bombeiros (Cobom). Um bombeiro atende as chamadas de dia e um outro à noite.

Eis a seguir, exemplos representativos dos tipos de ocorrências atendidas pelo 193, tais como foram registradas em referência à classificação das ocorrências no Cobom, nas fichas pelos bombeiros preenchidas:

Quadro 3-Ocorrências atendidas pelo Resgate - 1998, de 00h a 24h

\begin{tabular}{|c|c|c|}
\hline $19 / 02$ & $20 / 04$ & $01 / 05$ \\
\hline Vazamento GLP/fogo & Queda & $\begin{array}{l}\text { Agressão } \\
\text { obs.: vilima de arma de logo, } \\
\text { tentativa de roubo }\end{array}$ \\
\hline $\begin{array}{l}\text { Acidente de trânsito com vítma } \\
\text { obs.: suspeita fratura omoplatá }\end{array}$ & $\begin{array}{c}\text { Caso clínico } \\
\text { obs.: entorse na coluna }\end{array}$ & $\begin{array}{l}\text { Acidente de trânsío com vítima } \\
\text { obs.: vítima com ferinentos graves aa cabeça, } \\
\text { carro } x \text { molo }\end{array}$ \\
\hline $\begin{array}{l}\text { Queda } \\
\text { obs.: escorią̧ठes canela * }\end{array}$ & $\begin{array}{l}\text { Caso clinico } \\
\text { obs.: parada cardíaca, } \\
\text { atestada pelo Dr. X }\end{array}$ & $\begin{array}{l}\text { Aninal em local de risco } \\
\text { obs.: coetho tubulaçies }\end{array}$ \\
\hline Queda & $\begin{array}{l}\text { Acidente de trânstio com vilima } \\
\text { obs.: fratura de tibia e fibulia }\end{array}$ & $\begin{array}{l}\text { Aropelamento } \\
\text { obs.; vilima com escoriações braços }\end{array}$ \\
\hline Caso clínico & Parturiente & $\begin{array}{l}\text { Queda } \\
\text { obs.: vitima suspetia fratura columa }\end{array}$ \\
\hline $\begin{array}{l}\text { Transporte emergencial } \\
\text { obs.: transporte aié sua } \\
\text { residência - Siiio Sto. Antônio } \\
\text { Nova Columbia }\end{array}$ & $\begin{array}{l}\text { Queda } \\
\text { obs.: trauma na face }\end{array}$ & $\begin{array}{c}\text { Caso clínico } \\
\text { obs.: crise convusiva }\end{array}$ \\
\hline Caso clinico & $\begin{array}{c}\text { Incêndio } \\
\text { obs.: logo em lerreno baldio }\end{array}$ & Queda \\
\hline Queda & Animal perigoso & Animal agressivo \\
\hline Acidente de trânsito com vítima & $\begin{array}{l}\text { Caso clínico } \\
\text { obs.: crise convulsiva }\end{array}$ & $\begin{array}{l}\text { Atropelamento } \\
\text { obs.: escoriaçóes no rosto }\end{array}$ \\
\hline Atropelamento & $\begin{array}{l}\text { Caso clinico } \\
\text { obs.: febre }\end{array}$ & $\begin{array}{l}\text { Queda } \\
\text { obs : corte e contusão na cabeça }\end{array}$ \\
\hline Caso clinico & $\begin{array}{c}\text { Caso clnico } \\
\text { obs.: insuficiência respiratória }\end{array}$ & Exterminio inseto agressivo \\
\hline Atropelamento & Pariuriente & - \\
\hline Pessoa em local de risco & Exlerminio maribondo & - \\
\hline - & $\begin{array}{c}\text { Caso clínico } \\
\text { obs.: insuficiência respiratória }\end{array}$ & - \\
\hline - & Caso clinico & . \\
\hline
\end{tabular}

Fonte: Fichas de ocorrências do Serviço de Resgate de Marília. 
O serviço de resgate do Corpo de Bombeiros do $10^{\circ}$ Grupo de Intervenção (GI) de Marília tem a missão específica de prestar assistência às vítimas em situação de emergência. Ele conta com três viaturas para o atendimento das vítimas, denominadas Unidades de Resgate (UR-17, UR-163, UR-164), e com setenta bombeiros que receberam um treinamento em suporte básico de vida de $40 \mathrm{~h}$. As URs ficam sediadas nos quartéis do Corpo de Bombeiros, distribuidos estrategicamente em dois postos da cidade, para prestar um atendimento mais rápido, e operam geralmente com dois ou três bombeiros. No período noturno, durante os finais de semana e os feriados, alunos do quarto e quinto ano de medicina da Famema, que participam do projeto Alfa, ${ }^{8}$ integram a equipe de resgate e acompanham os bombeiros na suas saídas, um aluno por viatura.

Segundo dados do Anuário Estatístico do Corpo de Bombeiros, o Resgate de Marília atendeu, em 1997, 2.724 ocorrências, com um total de 2.649 vítimas, sendo dessas, 2.555 salvas. As ocorrências mais numerosas dizem respeito ao que os bombeiros classificam como "caso clínico", "acidente de trânsito com vitima", "queda", "atropelamento", "acidente pessoal".

Marilia conta ainda com o 192, um sistema de atendimento móvel municipal, a Central de Ambulâncias, oficialmente destinada a atender às urgências/emergências médicas, por meio de suas ambulâncias e deste número de telefone gratuito. As chamadas que caem no 192 são recebidas e triadas por uma escriturária e um mensageiro durante o dia, e por motoristas à noite.

A Central trabalha com três ambulâncias, ${ }^{9}$ dirigidas por motoristas que receberam treinamento de suporte básico de vida. As ambulâncias saem geralmente com um motorista; às vezes com dois, quando vão buscar uma pessoa cujo estado é avaliado, a partir dos elementos recolhidos no telefone, como necessitando da atuação de mais pessoas. Durante as sete noites da semana, alunos de enfermagem da Famema que participam do projeto Alfa dão plantões na Central e acompanham os motoristas em suas saídas noturnas, um aluno por viatura.

Dezoito pessoas trabalham para o 192: quinze motoristas, um mensageiro, uma escriturária e o responsável pela Central. Os motoristas trabalham a cada dois dias, três ficando no plantão de dia e três no plantão à noite. O sistema 192 atende um grande número de pedidos, como mostra a tabela seguinte:

Tabela 2 - Número de atendimentos mensais prestados pela Central de Ambulâncias em 1996, 1997 e nos oito primeiros meses de 1998

\begin{tabular}{c|c|c|c|c|c|c|c|c|c|c|c|c|c}
\hline Ano & Jan. & Fev. & Mar. & Abr. & Maio. & Jun. & JuL & Ago. & Set. & Out. & Nov. & Dez & TotA. \\
\hline 1996 & 1794 & 1827 & 1941 & 1939 & 1774 & 1718 & 2253 & 3224 & 2904 & 3002 & 1963 & 1713 & 26052 \\
\hline 1997 & 1643 & 1730 & 1771 & 1534 & 1692 & 1786 & 1668 & 1827 & 1797 & 1802 & 1609 & 1559 & 20418 \\
\hline 1998 & 1438 & 1218 & 1308 & 1375 & 1314 & 1371 & 1215 & 1301 & - & - & - & - & - \\
\hline
\end{tabular}

Fonte: Relatórios semanais, mensais e anuais da Central de Ambulâncias.

Também muito significativos da intensa atividade da Central são os quilômetros percorridos pelas ambulâncias e a quantidade de combustível por elas consumida para 
atender a população de Marília e distritos. Em 1996, elas rodaram $236.389 \mathrm{~km}$, e, em 1997 , 214.330. Mais detalhadamente, por exemplo, no mês de dezembro de 1996, em que prestaram 1.713 atendimentos, percorreram um total de $19.434 \mathrm{~km}$ e consumiram 4.084 litros de combustível. Um ano depois, em dezembro de 1997, passaram para 1.559 atendimentos prestados, elas rodaram $13.419 \mathrm{~km}$ e consumiram 4.152 litros de combustível. ${ }^{10}$

Entre as chamadas recebidas pela Central a propósito de um problema de saúde, a maioria diz respeito a casos classificados, pelos atendentes e motoristas, como 'psiquiátricos', 'clínicos' e 'obstétricos', e resultam no transporte dos pacientes para um pronto-socorro, geralmente o pronto-socorro do Hospital das Clínicas. As ambulâncias servem também como transporte social para altas hospitalares, retornos e exames médicos como bem mostra a tabela seguinte, representativa da natureza da demanda e dos serviços prestados pelo 192:

Tabela 3 - Motivos de saída das ambulâncias segundo classificação da Central para os meses de fevereiro - 1996, 1997, 1998

\begin{tabular}{|c|c|c|c|}
\hline Motivos de SAida das AmbULÃNCIAS & fev. de 1996 & fev. de 1997 & fev. de 1998 \\
\hline Pacientes de urgência para PS & $\begin{array}{c}1.069 \\
(58,51 \%) \\
\end{array}$ & $\begin{array}{c}1.037 \\
(59,94 \%)\end{array}$ & $\begin{array}{c}725 \\
(59,5 \%) \\
\end{array}$ \\
\hline Transferência inter-hospitalar & $\begin{array}{c}390 \\
(21,35 \%) \\
\end{array}$ & $\begin{array}{c}294 \\
(17 \%)\end{array}$ & $\begin{array}{c}159 \\
(13,05 \%)\end{array}$ \\
\hline Altas hospitalares levar para casa & $\begin{array}{c}249 \\
(13,63 \%) \\
\end{array}$ & $\begin{array}{c}292 \\
(16,88 \%) \\
\end{array}$ & $\begin{array}{c}232 \\
(19,05 \%) \\
\end{array}$ \\
\hline Saídas para distritos e outras cidades & $\begin{array}{c}86 \\
(4,70 \%) \\
\end{array}$ & $\begin{array}{c}64 \\
(3,70 \%) \\
\end{array}$ & $\begin{array}{c}72 \\
(5,9 \%)\end{array}$ \\
\hline Exames e retornos & $\begin{array}{c}33 \\
(1,81 \%) \\
\end{array}$ & $\begin{array}{c}43 \\
(2,48 \%) \\
\end{array}$ & $\begin{array}{c}30 \\
(2,5 \%) \\
\end{array}$ \\
\hline TOTAL & $\begin{array}{c}1.827 \\
(100 \%) \\
\end{array}$ & $\begin{array}{c}1.730 \\
(100 \%)\end{array}$ & $\begin{array}{c}1.218 \\
(100 \%)\end{array}$ \\
\hline
\end{tabular}

Fonte: Relatórios semanais, mensais e anuais da Central de Ambulâncias.

As saídas de ambulâncias são geralmente tão numerosas durante o dia quanto à noite. Porém, importa ressaltar que as chamadas de ajuda de urgência que resultam no transporte de pacientes para o pronto-socorro são mais numerosas durante o dia, enquanto as relativas a altas hospitalares são mais numerosas no período noturno. Isto se explica porque, à noite, as ambulâncias acabam preenchendo o vazio deixado pela ausência de meio de transporte público. Apesar de essa atividade não fazer parte de suas funções declaradas, as ambulâncias se tornam uma condução gratuita para os pacientes (e seus acompanhantes) que, tendo recebido alta hospitalar, não têm como voltar para casa. A tabela seguinte patenteia a modificação significativa do perfil da demanda e do atendimento entre o dia e a noite. 
Tabela 4 - Motivos de saída das ambulâncias nos períodos diurnos e noturnos do mês de fevereiro de 1998

\begin{tabular}{c|c|c|c|c|c}
\hline MotTVOS DE SAídA DAS AMBULÃNCIAS & Diurno & $\%$ & Noturno & $\%$ & ToTAL \\
\hline Pacientes de urgência para PS & 411 & 68,16 & 314 & 51,06 & $\begin{array}{c}725 \\
(59,5 \%)\end{array}$ \\
\hline Transferência inter-hospitalar & 80 & 13,27 & 79 & 12,85 & $\begin{array}{c}159 \\
(13,05 \%)\end{array}$ \\
\hline Altas hospitalares levar p/casa & 55 & 9,12 & 177 & 28,78 & $\begin{array}{c}232 \\
(19,05 \%)\end{array}$ \\
\hline Saídas para distritos e outras cidades & 31 & 5,14 & 41 & 6,66 & $\begin{array}{c}72 \\
(5,9 \%)\end{array}$ \\
\hline Exames e retornos & 26 & 4,31 & 04 & 0,65 & $\begin{array}{c}30 \\
(2,5 \%)\end{array}$ \\
\hline ToTAl. & 603 & 100 & 615 & 100 & $\begin{array}{c}1.218 \\
(100 \%)\end{array}$ \\
\hline
\end{tabular}

Fonte: Relatórios semanais, mensais e anuais da Central de Ambulâncias.

Entre as duas centrais de chamadas - o 193 e o 192 - é a segunda que, por razões que serão apontadas a seguir, veio a se tornar o segundo lugar de investigação privilegiado da pesquisa de campo, junto ao pronto-socorro do Hospital das Clínicas.

\section{Trabalho de Campo}

Para atingir as representações e práticas ligadas à urgência e à emergência em saúde, a escolha foi de um método qualitativo. Os dados de observação e de discurso nos quais se embasam as interpretações e análises aqui apresentadas foram recolhidos graças a um trabalho de campo, de tipo etnográfico, realizado entre novembro de 1997 e janeiro de 1999. Num primeiro momento, ele se desenvolveu sucessivamente em três locais da rede pública de atendimento às urgências e emergências de Marília: o prontosocorro do Hospital das Clínicas, a Central de chamadas dos Bombeiros (o 193) e a Central de Ambulâncias da prefeitura (o 192). Na medida em que neles confluem e manifestam-se, por excelência, demandas e atendimentos de urgência, esses lugares representam espaços privilegiados de acesso a observações e discursos de primeira importância para a pesquisa, relativos tanto à percepção e às práticas da urgência e da emergência quanto às interações entre os diversos atores implicados e a suas reações.

Uma vez investigados esses lugares, o trabalho de campo se prolongou fora deles, acompanhando os motoristas da Central de Ambulâncias em suas saídas para a rua. No domínio da urgência/emergência, a expressão da demanda e a realização da conseqüiente resposta em termos de atendimento (ou não atendimento), originam um processo cujo desenrolar se dá no tempo e no espaço e que se inicia muitas vezes fora 
do pronto-socorro, por exemplo, a partir de uma ligação para as centrais de chamadas." Apreender a rede de atendimento às urgências/emergências, não só a partir dos seus lugares fixos, mas a partir do movimento e da dinâmica que a animam, é fundamental para entender o processo na sua totalidade e para presenciar como nele se combinam práticas e representações diversas da urgência/emergência, umas compatíveis, outras conflituosas. Acompanhar os motoristas em suas saídas significa, também, ir com eles às casas das pessoas $\mathrm{e}$, assim, ter acesso a elementos inestimáveis de conhecimento dos contextos nos quais se inscrevem as chamadas de urgência.

\section{Observação Participante nos Locals de Atendimento}

Participei do cotidiano nos locais investigados, sobretudo durante o dia, e assim fui recolhendo aos poucos, durante meses, os dados da pesquisa. Devido às peculiaridades dos lugares, o trabalho de campo não se deu da mesma maneira em cada um deles. Ele foi se adaptando aos funcionamentos e ritmos das diversas realidades investigadas, suas atividades e pessoas, hierarquias e resistências. Como qualquer campo etnográfico, este foi se desenvolvendo com a construção progressiva das relações, segundo um movimento que emprestou suas vias e modalidades aos universos estudados.

No pronto-socorro, ${ }^{12}$ o lugar privilegiado da observação e da participação foi a parte aberta ao público, e nela vários espaços cujo trabalho de campo revelou as funções diferentes e as peculiaridades:

- a porta de entrada do pronto-socorro: um segurança fica ali, na parte de fora, $24 \mathrm{~h}$ por dia, e interroga as pessoas que querem entrar sobre o motivo de sua visita;

- a porta que separa a sala de espera adulto da área de atendimento médico adulto, interditada ao público: trata-se de um lugar altamente estratégico, pois é aí que os pacientes (e/ou seus acompanhantes) tentam obter do porteiro - que fica sempre em pé do lado da porta vigiando as entradas - um atendimento mais rápido; é aí também que os acompanhantes tentam conseguir informações sobre o que está acontecendo com o paciente quando ele já está dentro da área de atendimento. Enfim, é deste lugar cobiçado, que procuram vislumbrar o paciente, aproveitando-se das aberturas da porta;

- a recep̧̧ão: onde os pacientes (e/ou seus acompanhantes) vão preencher sua ficha quando chegam ao pronto-socorro;

- os espaços reservados à espera propriamente dita: salas de espera infantil e adulto, onde encontra-se um conjunto de cadeiras de plástico;

- a parte de fora do pronto-socorro: espécie de excrescência da sala de espera adulto, em contato e comunicação imediatos com ela pela porta de entrada. É um espaço ao ar livre aonde chegam, por uma rampa de acesso, tanto as pessioas que vem a pé ou de carro particular, quanto as viaturas do Resgate e as ambulâncias da prefeitura. Aí 
também ficam esperando pacientes e acompanhantes, mais ou menos numerosos, segundo a importância da afluência.

No pronto-socorro, as partes físicas de atendimento médico adulto e infantil também foram lugares de investigação. Entretanto, importa sublinhar, que apesar de ter sido formalmente aceita nestes lugares desde o inicio da pesquisa, ${ }^{13}$ o trabalho de campo foi aí dificultado pela resistência perceptível dos profissionais da saúde, geralmente atentos a seus discursos e atitudes em minha presença. Vários comportamen$\operatorname{tos}^{14}$ traduziram seu incômodo (aliás, recíproco) e sua autovigilância. ${ }^{15}$ Recolhi e interpretei os dados, conseguidos nesses lugares, consciente dessa alteração que, aliás, diminuiu bastante com o tempo. ${ }^{16}$

Ao contrário do que aconteceu nas áreas de atendimento médico, a integração na parte aberta ao público foi fácil. Consegui transformar minha presença, de início excepcional e estranha, em uma presença familiar e comum. Não encontrei dificuldade em entrar em contato com os usuários, em desenvolver com eles uma sociabilidade de relações ordinárias. Nas salas de espera, onde eram geralmente numerosos, era percebida como paciente ou acompanhante de doente. Sendo a espera geralmente demorada, muitas são as pessoas que procuram uma conversa para passar o tempo e que abordam, assim, de maneira espontânea, assuntos interessando diretamente a pesquisa: contam os motivos de sua presença, falam do problema que as levou para o pronto-socorro, relatam suas circunstâncias, história e conseqüências, mencionam as pessoas e os acontecimentos envolvidos etc. Expressam sua inquietação, suas queixas, seu aborrecimento... A parte de fora, por ser um espaço onde muitas pessoas saem para conversar e fumar um cigarro, também favoreceu bastante os contatos e as conversas.

Nesses espaços públicos do pronto-socorro, a integração foi facilitada pelo simples fato de que só precisava participar da espera, ficar disponivel e mostrar interesse para qualquer conversa para conseguir um papel local. Aproveitando-me dessa situação, não revelei os motivos da minha presença às pessoas que não os questionaram, o que foi o caso da maioria delas.

Com os seguranças, os porteiros e as recepcionistas, a situação foi diferente, pois, ao contrário dos usuários, esses profissionais do pronto-socorro me viam todo dia. Para eles, expliquei que era uma pesquisadora francesa, antropóloga, interessada em conhecer o funcionamento de um pronto-socorro brasileiro, em saber quem o procurava e para que tipo de problemas, e como eram realizados os atendimentos. Exceção feita a um porteiro que manifestou antipatia durante as primeiras semanas, não encontrei resistência por parte desse pessoal, que se mostrou bastante prestativo e cooperador. Foi o caso, especialmente, dos seguranças, que, no intuito de auxiliar-me na pesquisa, tomavam a iniciativa de chamar minha atenção sobre coisas que podia estar ignorando, de informar-me sobre acontecimentos ocorridos em minha ausência e de compartilhar comigo o entendimento que tinham das situações que presenciávamos juntos ou não. A partir de nossas numerosas e longas conversas, ${ }^{17}$ construímos relações descontraídas e de confiança. A mesma coisa aconteceu com as recepcionistas com as quais passei muito tempo. 
Os dados conseguidos no pronto-socorro foram essencialmente recolhidos a partir da observação, da escuta de conversas e comentários e da participação de conversas informais e situações variadas. As poucas entrevistas realizadas foram com médicos e enfermeiras. Com os usuários e os profissionais não médicos do prontosocorro, não recorri à técnica das entrevistas, mesmo que não diretivas. ${ }^{18} \mathrm{Com}$ o objetivo de intervir, o mínimo possível, em seus discursos e comportamentos, preferi me deixar guiar pelos assuntos espontaneamente abordados nas conversas informais, tentando orientá-los para questões que interessavam mais diretamente a pesquisa, quando era propício e oportuno. Da mesma maneira, não usei gravadores, ainda menos máquina fotográfica e filmadora, cujo uso dentro do pronto-socorro era proibido. ${ }^{19}$

Depois de cinco meses, o trabalho de campo se deslocou para as centrais de chamadas. Nelas, o objetivo principal era recolher o conteúdo das conversas telefônicas. ${ }^{20}$ Por isso, precisava escutar as falas não só dos atendentes, mas também dos solicitante, e, se possível, gravá-las para poder conservar os enunciados exatos e seu encadeamento nas conversas.

No 192, o chefe da Central instalou para mim um telefone que permitiu a escuta dos solicitantes nas suas conversas com os atendentes. Mas, devido a limitações técnicas, a gravação das falas foi muito rudimentar e obtida graças a um pequeno gravador que eu encostava no telefone o tempo que durava a ligação, o que não só dificultou as gravações, mas também impossibilitou gravar as chamadas recebidas durante minha ausência. No 193, não foi possível montar um sistema que me permitisse escutar a fala do solicitante no momento da ligação. Entretanto, um bombeiro instalou um sistema que possibilitou gravar todas as chamadas recebidas de dia e à noite, eu estando ou não presente.

O trabalho de campo nas centrais também permitiu entender o funcionamento e as atividades desses lugares, conhecer seus vários atores, observar as modalidades do desencadeamento (ou não) das respostas técnicas suscitadas pelas chamadas e escutar as conversas por rádio entre atendentes e motoristas. Favoreceu, igualmente, o estabelecimento progressivo de relações de confiança com os motoristas, relações muito importantes para a continuação do trabalho de campo, visto que minha intenção depois era acompanhá-los nas suas saídas.

\section{Observaciano Participante vas Equipes Móveis}

Uma vez os lugares físicos e fixos da urgência/emergência investigados, o trabalho de campo saiu de seus muros para entrar no movimento das equipes móveis que prestam socorro às pessoas no lugar onde se encontram (casa, rua, lugares públicos, de trabalho etc.). A participação na dinâmica da ajuda móvel de urgência não só permitiu apreender o desenvolvimento inteiro do processo, ${ }^{21}$ mas também comparar o conteúdo verbal e emocional das chamadas ${ }^{22}$ com a realidade das situações e dos estados dos doentes (vítimas). Comparação interessantíssima, na medida em que revelou, na maioria dos casos, diferenças importantes e significativas entre o que é descrito pelos solicitantes no telefone e o que os motoristas encontram no lugar. 
Saí de viatura de maio a setembro de 1998, e ainda em janeiro de 1999, principalmente com os motoristas de ambulâncias do 192, e muito pouco com os bombeiros do 193. Essa situação foi devida à falta de tempo para acompanhar igualmente uns e outros e, sobretudo, ao fato de a Central do Resgate encontrar-se em um lugar afastado dos lugares dos quais partem suas viaturas. Estas ficam em vários outros pontos da cidade para poder atender mais rápido, segundo o local da ocorrência. Para a comparação, ambicionada, entre o conteúdo da chamada e a situação encontrada no lugar, a Central do 192 apresentava a grande vantagem de ser, ao mesmo tempo, o lugar de recepção das chamadas (cujo conteúdo podia escutar) e de partida das ambulâncias.

Nessa segunda fase do trabalho de campo, marcada pelo movimento, utilizei bastante a filmadora. Do ponto de vista metodológico, ela representava o instrumento ideal para acompanhar, guardar e restituir a dinâmica da qual participavam os deslocamentos e as ações, para gravar os comportamentos e falas dos protagonistas, para identificar momentos e espaços muito significativos de suas interações. ${ }^{23}$ No fim do trabalho de campo, filmei também com o intuito de finalizar a pesquisa com um documento videográfico sobre a realidade do trabalho efetuado pela Central de Ambulâncias, seus atendentes e motoristas. Este projeto desembocou na realização de Urgences, um documentário etnográfico, cuja proposta central é mostrar para que tipo de problemas ou de situações as pessoas recorrem ao 192 e, através dos vários casos apresentados, desvendar sua concepção da urgência.

\section{NoTAS}

1 Alto Cafezal e Vila Barbosa, criados em 1923, e Marília, criado em 1928.

2 Dados do Censo Demográfico de 2000 da Fundação Instituto Brasileiro de Geografia e Estatística (IBGE). A taxa de urbanização é de $96,14 \%$, a taxa de alfabetização, de $93,9 \%$, e a taxa de crescimento populacional, de 2,32, entre 1991 e 2000.

3 Todos os dados tratados neste livro se reportam ao período da realização do campo.

4 É classificada como Posto de Saúde (Unidade Básica de Saúde - UBS), a unidade destinada a prestar assistência sanitária de forma programada a uma população determinada, por pessoa de nível médio ou elementar, utilizando técnicas apropriadas e esquemas padronizados de atendimento. é classificada como Centro de Saúde, a unidade destinada a prestar assistência sanitária de forma programada a uma população determinada, nas quatro especialidades básicas. A assistência médica deve ser permanente e prestada por médicos generalistas e/ou especialistas.

5 Cadastrados no Sistema de Informações Ambulatoriais do Sistema único de Saúde (SIA/SUS): seis de patologia clínica, três de radiologia, três de ultra-sonografia, três de endoscopia, um de dispensação de órtese e prótese, dois de tratamento dialítico e cinco de fisioterapia.

6 Quando perguntei ao bombeiro que atendia as chamadas na Central o significado de 'canela', ele deu risada e comentou que quem tinha escrito isso era um ignorante, pois 'canela' é uma palavra popular que não deveria ter usado. 
7 Em relação a essa ocorrência, o mesmo bombeiro comentou: "é muito raro o Resgate fazer isso, deve ser alguém que conhece alguém, que tem o poder de obter coisas dos bombeiros, que fez essa chamada".

8 O Projeto Alfa foi fundado em 1990, quando o Ministério da Saúde elaborou um Programa de Enfrentamento às Emergências Médicas. Em Marília, ele é composto pelo corpo docente do curso de medicina e enfermagem da Famema e teve suas diretrizes baseadas em um projeto, de mesmo nome, originário da cidade de Santos/SP.

9 A Central possui mais ambulâncias, mas, durante o dia como à noite, só funciona com três. Devido a problemas mecânicos que ocorrem freqüentemente com esses veículos, não é raro a Central funcionar com duas ambulâncias e às vezes com uma só. Na época da pesquisa de campo, não havia serviço de suporte avançado de vida (UTI-móvel) público, atendendo o SUS, no município de Marília.

10 Dados coletados nos relatórios semanais, mensais e anuais da Central.

1! Neste caso, o pronto-socorro vem a se tornar o lugar não da primeira, mas da última etapa do processo.

12 Ver o mapa do pronto-socorro no final em anexo.

13 Por autorização oficial do próprio hospital.

14 Em relação a mim: frieza, distância, rapidez das interações, contatos evitados, interrupção das conversas ao chegar, trocas e encontros fugazes de olhares... Sobretudo no início do trabalho de campo, penso ter também suscitado modificações nas atitudes, por exemplo, na maneira de certos médicos e enfermeiros se relacionarem com os pacientes ou os acompanhantes. A comparação com observações ulteriores confirmou a impressão que estavam mais disponíveis, atentos e pacientes com as pessoas que procuravam conversar com eles, quando eu estava por perto.

15 O que não tem nada de excepcional, na medida em que como apontam também Beaud e Weber (1997: 10), no "mundo dos dominantes (empresários, profissões liberais, médicas, intelectuais etc...), o trabalho de campo é difícil, pois as pessoas sabem se proteger melhor do olhar próximo do antropólogo, seja dificultando o acesso ao campo, seja aceitando formas mais controladas de colaboração".

16 Com o desenrolar do trabalho de campo, que tornou minha presença mais costumeira, a auto-vigilância, difícil de ser mantida por muito tempo, baixou; o que me permitiu ouvir falas e observar situações, interações e atos, mais próximos do que são em situação 'habitual'.

17 Conversar com os seguranças e porteiros que ficavam parados horas em pé no mesmo lugar (ao lado das portas) não representava uma atitude esquisita na medida em que é bastante comum os usuários, na espera, conversarem com eles também. Com alguns seguranças, as conversas aconteceram também fora do pronto-socorro em lanchonetes que rodeiam o hospital, depois do horário de trabalho.

18 Sem aprofundar aqui essa postura metodológica, pois leva a discussōes que fogem de nosso assunto, importa deixar claro que as entrevistas foram voluntariamente pouco utilizadas nesta pesquisa, por serem um instrumento de coleta dos dados de 
discurso muito problemático, no que diz respeito ao conteúdo e à interpretação das respostas (os enunciados) que suscita.

19 Mas filmei a parte de fora na segunda fase do trabalho de campo, quando chegava ao pronto-socorro com as ambulâncias do 192.

20 Também interessava presenciar as reações e comentários dos atendentes depois das ligações.

21 Como é mobilizado e acionado, desde o seu desencadeamento através da chamada de urgência, até a entrega do paciente transportado ao pronto-socorro; quem são os vários atores que atuam nele (motoristas, bombeiros, polícia) e suas relações.

22 Descrição da situação de risco e dos sintomas do doente, identidade declarada do solicitante, nível de angústia etc.

23 Por exemplo, o momento da negociação entre motoristas e solicitantes, que acontece geralmente na chegada da ambulância, no portão de entrada das casas, longe da pessoa para quem o 192 foi chamado. 